Revue

Revue de l'histoire des religions

de Ihistoire des religions

Genève, refuge et migrations ( $\mathrm{XVI} \mathrm{e}^{\mathrm{e}} \mathrm{XVII}{ }^{\mathrm{e}}$ siècles)

Jules RACINE SAINT-JACQUES, L'honneur et la foi. Le droit de résistance chez les réformés français (1536-1581)

Genève, Droz, 2012

Chrystel Bernat

\title{
CpenEdition
}

Journals

Édition électronique

URL : http://journals.openedition.org/rhr/8375

DOI : 10.4000/rhr.8375

ISSN : 2105-2573

Éditeur

Armand Colin

Édition imprimée

Date de publication : 1 mars 2015

Pagination : 113-116

ISBN : 9782200929657

ISSN : 0035-1423

Référence électronique

Chrystel Bernat, « Jules Racine SaINT-JAcques, L'honneur et la foi. Le droit de résistance chez les réformés français (1536-1581) », Revue de l'histoire des religions [En ligne], 1 | 2015, mis en ligne le , consulté le 22 septembre 2020. URL : http://journals.openedition.org/rhr/8375; DOI : https://doi.org/10.4000/rhr 8375

Ce document a été généré automatiquement le 22 septembre 2020.

Tous droits réservés 


\section{Jules RACINE SAINT-JACQUES, L'honneur et la foi. Le droit de résistance chez les réformés français (1536-1581)}

Genève, Droz, 2012

\section{Chrystel Bernat}

\section{RÉFÉRENCE}

Jules RACINE SAINT-JACQUES, L'honneur et la foi. Le droit de résistance chez les réformés français (1536-1581), Genève, Droz, 2012, 22 cm, 218 p., 47 €, ISBN 978-2-600-01587-5.

1 Les Cahiers d'Humanisme et Renaissance publient les travaux de maitrise d'un doctorant de l'Université Laval, à Québec, dirigés par Michel De Waele, doyen de la Faculté des lettres et des sciences humaines. L'auteur (dorénavant J.R.S.-J.) se fixe pour objectif de revisiter, de Calvin à Duplessis-Mornay, l'élaboration théologico-politique des théories de l'obéissance civile et du droit de résistance au prince parmi les écrits réformés français, et leur articulation à la revendication de fidélité à Dieu. Ce petit volume, dont le propos s'agence en trois chapitres, comporte aussi un index et une bibliographie qui, selon les thèmes, aurait mérité d'être actualisée (celle relative à Calvin aurait gagné à intégrer les récentes études consacrées à la pensée du réformateur).

2 Les propos introductifs précisent l'enjeu du mémoire qui consiste à reconsidérer la formation de la pensée politique huguenote dans son articulation au choc de la SaintBarthélemy. Au sein d'une historiographie qui a durablement favorisé la production littéraire postérieure au massacre de 1572, l'auteur entend réévaluer, dans le sillage des travaux de D. R. Kelley, la filiation des textes ante et post barthélemistes en s'emparant des sources réformées des années 1560, appréhendées comme celles de la structuration du parti huguenot autour de Condé. Prenant acte de la redistribution chronologique et archivistique de la pensée monarchomaque introduite par les enquêtes de P.-A. Mellet, il examine l'évolution des idées au cours des trois premières guerres de Religion 
(longtemps délaissées au motif d'une moindre valeur heuristique pour le sujet), avec pour ambition de jeter, à la suite de ses aînés, un pont entre les pensées calvinienne et monarchomaque. En explorant le corpus compris entre la Conjuration d'Amboise de 1560 et la déflagration de 1572, l'auteur souhaite évaluer dans quelle mesure la justification de la violence réformée, demeura, entre ces dates, fidèle aux préceptes calviniens, tout en présageant de la pensée de résistance armée au tyran qui prévaut ensuite parmi les héritiers les plus radicaux du réformateur. S'emparant de cette décennie décisive, J.R.S.-J. ambitionne un " essai » visant à " éclairer d'une lumière plus franche » la théorie monarchomaque de la résistance, délestée depuis R. Kingdon et P.A. Mellet de la «thèse du traumatisme" fondateur et structurant de la SaintBarthélemy, attaquée dès 1967 par R. E. Giesey.

3 Le premier volet, consacré aux "ambiguités de la pensée politique calvinienne", entend démontrer que le discours de Calvin a pu servir, au prix d'entorses rhétoriques, à légitimer la révolte armée, tout en convenant aussitôt que la contestation du pouvoir (et, ce faisant, le contournement de l'interdit moral calvinien) s'affirme à partir de 1559 , dès lors qu'en changeant de héraut le discours protestant change de registre - la noblesse lui faisant quitter le terrain théologique pour le mener sur le terrain politique, glissant de la défense de la foi à celle du bien public (p. 61-62).

4 Le chapitre intermédiaire, redevable notamment des travaux d'A. Jouanna, s'intéresse aux «facettes du devoir nobiliaire» soulignant combien la défense des lois fondamentales du royaume et la protection de l'innocence de l'enfant-roi ordonnent le discours réformé français contre l'usurpation du pouvoir par les factions catholiques (p. 74, 88) avant que ne s'impose le motif de la liberté de conscience (p. 99). Considérant qu'il y a un avant et un après Henri II (la propulsion des Guises au sommet de la monarchie faisant «basculer le mouvement réformé de l'ambivalence calvinienne aux convictions nobiliaires »), l'auteur s'écarte de l'historiographie qui tisse un lien entre le discours calvinien et la promotion de la violence réformée, en défendant l'idée d'un processus d'émancipation des considérations théologiques du pouvoir (p. 111-112).

5 L'ultime section, réservée à la " gestation et maturation d'une théorie de la résistance au tyran ", qui analyse la "parenté idéelle » des manifestes condéens et des pamphlets des années 1560 avec les textes monarchomaques de Hotman, Bèze, Mornay, confirme la réévaluation pionnière de R. E. Giesey contre la "trauma thesis». La théorie contractuelle du pouvoir imprègne les discours huguenots des années 1564-1570. La vision d'une monarchie nécessairement consultative et le principe d'une souveraineté partagée s'imposeraient dès 1564 lorsque les juristes de la cause condéenne en introduisent l'idée dans la rhétorique constitutionnaliste nobiliaire et valorisent le caractère électif de la monarchie française (p. 136, 148). Mais faut-il, s'interroge J.R.S.$\mathrm{J}$, y lire la première expression d'une théorie monarchomaque tandis que jamais l'intention des auteurs ne se porte contre la personne du roi mais contre ses conseillers fallacieux (p.149) ? La violence n'est pas, en cette décennie, orientée expressément contre le souverain (p. 170). Se distanciant de l'historiographie actuelle qui valorise, avec P.-A. Mellet, un tel décentrage ante caedes, l'auteur observe qu'il est malaisé de reconnaître dans ces premiers textes calvinistes une théorisation aboutie du droit de résistance légitime à la tyrannie royale (p.150). Tout au plus consent-il à un «embryon» de théorie en filigrane des textes antérieurs à 1572. Néanmoins, il convient, avec D. Crouzet, de velléités subversives précoces du discours condéen, qui seraient comme intrinsèques à la Réforme (p.173). Or, les témoignages de défiance à 
l'égard du pouvoir et les avertissements adressés au souverain par le biais du récit du courroux divin pesant sur les princes amateurs d'injustice de la trempe d'Achab équivalent-ils à une «tentation révolutionnaire » (p. 173), là où continue de prévaloir la conception calvinienne de l'ordre politique? L'auteur balance au gré des discours, autant que l'impose la complexité du sujet, concluant in fine que le droit de résistance à la tyrannie ne fut « jamais présenté de manière explicite et élaborée avant le massacre de la Saint-Barthélemy » : si les fondements conceptuels du contractualisme, écrit-il, sont jetés dès avant 1572 , aucune modalité de résistance dirigée contre la figure du roi ne s'affirme avant cette date (p.184). Concédant que le carnage a infléchi le discours politique des réformés sur l'obéissance due au roi, l'auteur insiste sur le fait qu'il ne l'a pas initié, seulement cristallisé (p. 185). Et l'auteur de suivre pourtant D. Crouzet sur les "propositions subversives» des tout premiers pamphlets huguenots qui auraient été suffisamment inquiétantes pour amener le pouvoir à vouloir en anéantir le danger, faisant ainsi de la «critique préexistante " protestante l'une des courroies actives du carnage d'août 1572. L'analyse est aussi l'occasion d'affirmer le caractère pluriel des théories monarchomaques de résistance que l'emploi fréquent du singulier obstrue (p. 169), tandis que dominent une chronologie de rédaction discordante des objectifs et des formes littéraires disparates (p. 193).

6 Après d'autres, l'auteur tient 1572 pour date de glissement de la théorie réformée du droit de résistance qui, d'abord orientée contre l'entourage du roi (tyran d'usurpation), en vient à se tourner contre le monarque (tyran d'exercice). À la suite de H. Daussy, il lie l'oscillation huguenote à la tension entre Romains 13 et Actes V, 29 qui parcourt le message politico-religieux de Calvin relatif à l'obéissance au roi et à l'allégeance à Dieu.

La violence réformée, d'abord exercée au motif de la défense de la couronne menacée par le contexte successoral (minorité des héritiers d'Henri II) et l'influence néfaste des conseillers catholiques (issus des cercles guisards), relèverait à partir de 1567 de la défiance envers la passivité complice du roi à l'égard des exactions commises contre ses sujets réformés : en un déplacement du dilemme moral des huguenots sur le champ plus strictement politique, la stratégie discursive des combattants réformés renouerait avec la notion de souveraineté populaire qui aurait imposé, pour sauver la monarchie française exposée à l'aliénation du roi, moins de la soustraire à une emprise catholique funeste que de substituer la force à une défaillance jugée fatale au royaume. L'attitude «belliqueuse » des réformés s'endosserait alors au titre de la défense du bien public (p.191). L'évolution suffit-elle pour réviser la chronologie de la pensée proprement dissidente ? Non, répond l'auteur : la « préfiguration » des idées monarchomaques chez Jean de Coras (A. Jouanna) ne permet pas de disjoindre le "moment monarchomaque " de la Saint-Barthélemy pour l'étendre aux textes de la première décennie des guerres de Religion (p. 192). L'étude a l'avantage de relancer la discussion sur la nomenclature actuelle du concept monarchomaque et de souligner combien son sens élastique, posé sans rigueur conceptuelle il y a quatre siècles par W. Barclay, demeure problématique (p. 194-195). Avec l'audace du jeune chercheur, J.R.S.-J. en appelle à reléguer « aux oubliettes» (p.197) le terme au profit de celui de "théorie alter-monarchiste de la résistance » qui présenterait l'avantage d'englober tous les textes produits lors des guerres de Religion pour justifier la violence huguenote - au risque, semble-t-il, de disqualifier toute réflexion sur les points de basculement de l'histoire des idées. Si l'on ne peut que souscrire au souci d'exactitude sémiologique qui engage à réinvestir et 
affiner le concept, celui proposé ne survalorise-t-il pas la lecture républicanisante du calvinisme au détriment de son loyalisme tenace au système monarchique?

\section{AUTEURS}

\section{CHRYSTEL BERNAT}

Institut protestant de théologie, Montpellier. 